\title{
Cooling on Photovoltaic Panel Using Forced Air Convection Induced by DC Fan
}

\author{
A.R. Amelia*, Y.M. Irwan ${ }^{*}$, M. Irwanto ${ }^{*}$ W.Z. Leow ${ }^{*}$, N. Gomesh ${ }^{*}$, I. Safwati ${ }^{* *}$, M.A.M. Anuar ${ }^{* * *}$ \\ ${ }^{*}$ Centre of Excellence for Renewable Energy, School of Electrical System Engineering, University Malaysia Perlis \\ (UniMAP), Malaysia \\ ** Institute of Engineering Mathematics, University Malaysia Perlis, (UniMAP), Malaysia \\ ${ }^{* * *}$ Faculty of Electrical \& Automotion Engineering Technology Tati University Collage (TATI), Malaysia
}

\begin{tabular}{l}
\hline Article Info \\
\hline Article history: \\
Received Oct 2, 2015 \\
Revised Nov 27, 2015 \\
Accepted Dec 18, 2015
\end{tabular}

\section{Keyword:}

Direct-current (DC) fan Photovoltaic (PV) panel PV panel temperature Solar radiation

\begin{abstract}
Photovoltaic (PV) panel is the heart of solar system generally has a low energy conversion efficiency available in the market. PV panel temperature control is the main key to keeping the PV panel operate efficiently. This paper presented the great influenced of the cooling system in reduced PV panel temperature. A cooling system has been developed based on forced convection induced by fans as cooling mechanism. DC fan was attached at the back side of PV panel will extract the heat energy distributed and cool down the PV panel. The working operation of DC fan controlled by the PIC18F4550 micro controller, which is depending on the average value of PV panel temperature. Experiments were performed with and without cooling mechanism attached to the backside PV panel. The whole PV system was subsequently evaluated in outdoor weather conditions. As a result, it is concluded that there is an optimum number of DC fans required as cooling mechanism in producing efficient electrical output from a PV panel. The study clearly shows how cooling mechanism improves the performance of PV panel at the hot climatic weather. In short, the reduction of PV panel temperature is very important to keep its performance operated efficiently.
\end{abstract}

Copyright @ 2016 Institute of Advanced Engineering and Science. All rights reserved.

\section{Corresponding Author:}

\author{
A.R. Amelia, \\ Center of Excellence for Renewable Energy, \\ School of Electrical System Engineering, \\ University Malaysia Perlis (UniMAP), Malaysia. \\ Email: amelia_razak87@yahoo.com
}

\section{INTRODUCTION}

A renewable energy resource is going to be a main substitute for fossil fuels in recent years for their clean and renewable nature. Increasing world-wide energy demand and fossil-fuel depletion has been major driving forces for the researchers to be focused on renewable sources of energy [1]. Solar energy is the most promising renewable energy sources that the world needs. Sun as the main resources for this existing energy is utilized in one way by PV panels.

Generally, PV panels are categorized as the main component in developing solar system. MostPV panels have the major part of investment cost compared to another component. Thus, return of investment for development solar system is directly dependent electrical energy generated from PV panels. However, at present, the biggest problems encountered by using PV panels lie in the relatively lower electrical efficiency. Low efficiency of PV panels is regarding on their low energy conversion efficiency. The conversion efficiency depends on the type of PV panel used and the environmental conditions [2]. PV panels tend to be converted a part of the incident solar light into electrical energy the rest being wasted as heat. This heat is lost to the surroundings from the front surface and in the air gap at the back surface by convection and radiation. The heat generated induces an increase in the PV operating temperature. Due to electron transport properties, 
increasing in PV operating temperature will reduce the output generated by the PV panels dramatically. For example, crystalline silicon solar cells have a typical power temperature coefficient of $-0.5 \%$ for every $1^{\circ} \mathrm{C}$ rise in operating temperature [3]. Besides, increment in cell temperature leads to significant reduction in open-circuit voltage (Voc) caused by decreases in the band gap of the semiconductor. Therefore, the PV panel must be able to operateat low conversion operating temperature in order to generate efficient output power. To minimize the temperature degradation of the output power, the heat energy produced must be dissipated. Thus, the operating temperature can be kept close to the ambient temperature while decreasing in temperature difference.

In order to obtain efficient output power from PV panel, it is necessary to cool the PV panels by extracting the extra heat from the cell assembly in some way. This present paper focused on cooling mechanism that used air as cooling medium to reduce the temperature of PV panel. Air cooling technology either force or natural convection can be used to cool down the temperature of PV panel. H.G. Teo et al. carried out a study on the comparison of the electrical efficiency of the PV panel with and without cooling. Increasing the efficiency of solar cells was proved under cooling conditions [4]. Z. Farhana et al. reduced the temperature of solar panel by $40 \%$ when using a DC brushless fan as a cooling device. A DC brushless fan with inlet/outlet manifold design for uniform airflow distribution was attached at the back of PV panel [5]. O. Zogou and H. Stapountzis investigated the transient character of real world building integrated photovoltaic (BIPV) operated by the three different operated modes. The increasing fan capacity increases overall heat transfer and PV panel cooling performance [6]. Y.M. Irwan et al. investigated the effect of the air cooling mechanisms under indoor testing, which used halogen lamps as a light source. The impact of the air cooling mechanism was analyzed under different level of solar radiation and surrounding temperature. By using a DC fan to cool down the PV panel temperature, the power output has been observed with increasing solar radiation [7]. S. K. Natarajan et al. developed a 2D numerical model to predict the temperature (cell and lens) under peak solar illumination. The performance of cell temperature was tested by comparing without and with three numbers of fins [8].

In this study, a cooling mechanism by forced air convection is developed and presented. The main objective of this study is to investigate the performance output of the PV panel with the existing of the different number of DC fans as cooling mechanism. Besides, the PV panel without cooling mechanism has been performed in order to make a comparison with the existing cooling systems. The purpose of the study is also to investigate the effect of the different number of DC fans which act as cooling mechanism for a PV panel.

\section{EXPERIMENTAL AND SYSTEM CONFIGURATION}

The experimental setup has been developed to investigate the effect of the cooling system for PV panel in the outdoor operation. Further details about experimental design have been discussed in this section. This section consists three parts, which described the whole development and testing for PV system without or with cooling experimental. The first sectionhas elaborated details about the process of PV system with the existing automatic cooling mechanism. Then, the construction of thecooling mechanism has been discussed. The last section was describing how all data has been collected during the experimental day.

\subsection{Overall PV System Setup}

This experimental setup was designed to explore the application of the cooling system in reducing PV panel temperature due to improve the performance output of the PV panels. To analyze the whole performance of PV panels, a PV system was designed as illustrated in Figure 1. According to the figure, the system was developed based on stand-alone PV system installation requirement which independent of the electric utility grid operation. A PV panel acts as a generator to generate DC power to the direct current load. Each PV panel has a $100 \mathrm{~W}$ rating of maximum power output. The electricity generated by the PV panel was then stored in a deep cycle rechargeable battery. During operation, the controller features also used to protect the battery used from overcharging or deep discharge. Then, two units of DC lamp with each power rating at $5 \mathrm{~W}$ are used as a load demand. For cooling mechanism, the required DC fan whopowers up by a battery, extracted air from the surroundings to cool the panels. This cooling mechanism is very attractive because automatically operated, which leads to the energy saving. The operation of DC fan will be controlled by a PIC18F4550micro controller. This micro controller acts as a signal to ask the DC fan to operate. In addition, the required DC fan will not operate 24 hours, but only runs at certain certified PV operating temperature. For this study, all DC fans used will run when the operating PV temperature reaches $35^{\circ} \mathrm{C}$ and above since the average daily ambient temperature in Malaysia is at $35^{\circ} \mathrm{C}$ [9]. 
(1)

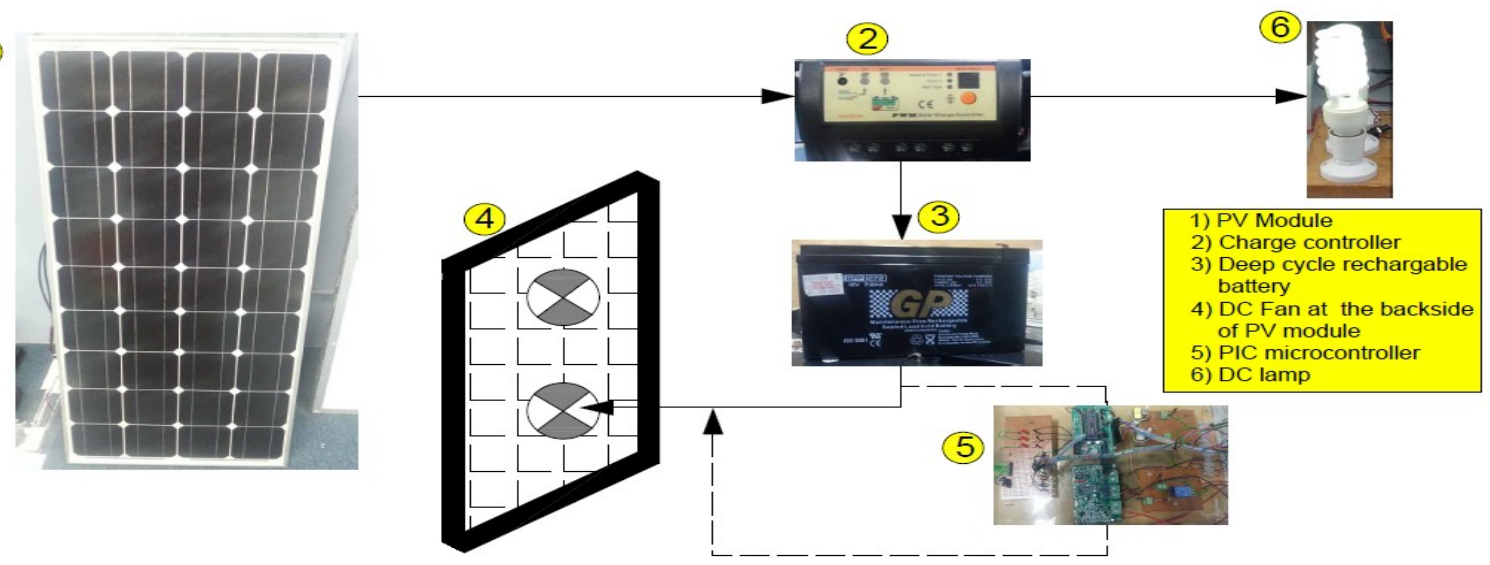

Figure1. Overall PV system with the cooling system

\subsection{Installation of DC Fan Cooling Mechanism}

Figure 2 illustrates the DC fan cooling development. The cooling mechanism with PV panel installation is shown as in Figure 2 (a). Each design of DC fan cooling mechanism was attached at the back side of PV panel as to extract heat produced. The DC fan was installed with zinc sheet, which can work as the heat transfer application is shown in given Figure 2 (b). There is four mode operation of cooling mechanism were developed. Each mode operation was installed by a different unit of DC fan, which are one to four units for each PV panel. The position of DC fan installed with "turn in circulation" which means air from outside enters to the backside of PV panel. Normally, cool air has high density compared to the hot air. Thus, cool air from the outside environment will cool down the PV panel by removing the hot air produced through the panel. For this experiment, all DC fans will have the same specification. Figure 2 (c) shows the physical aspect of DC fan used as a cooling device. Each DC fan has $12 \mathrm{~V}$ of nominal voltage with rating current of $0.07 \pm 10 \% \mathrm{~A}$. The power input required to run is $0.84 \mathrm{~W}$ for each fan. Furthermore, each DC fan can remove heat produced with their maximum airflow characteristic of 44.7 cubic feet per minute (CFM) respectively.
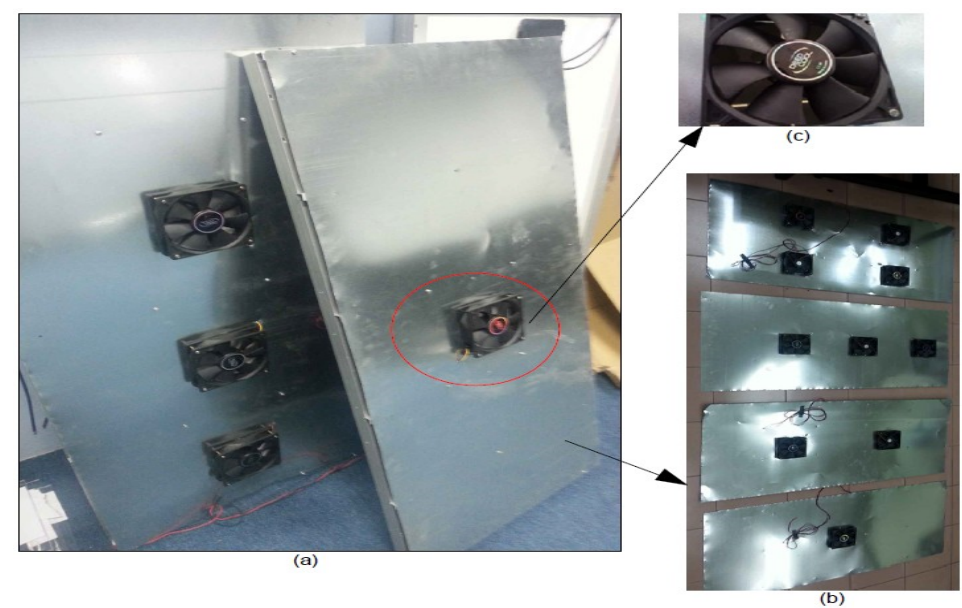

Figure 2. The development of DC fan cooling mechanism

\subsection{Test Procedure and Data Actuation}

Measurements for PV panel performance evaluation without cooling and with cooling were recorded during clear days at the Centre of Excellence for Renewable Energy (CERE), in University Malaysia Perlis (UniMAP), Malaysia in April 2015. One of the reasons for experimental conducted in April caused by experienced in such high temperature by means the sun is vertically overhead the equatorial region from mid- 
February to mid-April. The photographic view at the present experimental PV panels is shown in Figure 3 respectively.

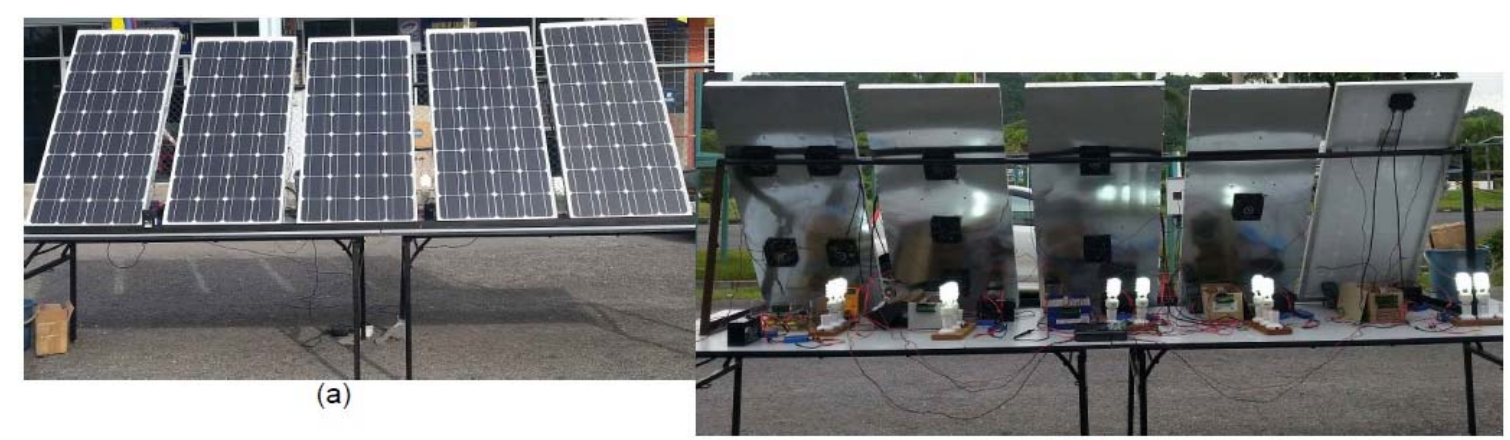

(b)

Figure 3. The outdoor experimental of PV system with and without cooling system

An analysis of the repeatability of the measurements was performed due to ensure reliability results produced. Thus, the experiment was conducted for 8 hours from 9.00 am to $5.00 \mathrm{pm}$ at 10 -minute intervals. The surrounding environmental temperature (ambient temperature) was measured using a digital temperature sensor. Temperature measurements are most the important measurement in this experiment due to investigate the impact of cooling system application. About four units of temperature sensor (LM35) are installed on the back side of thepanel as purpose to determine the average PV operating temperature distributed from a PV panel. Besides, the thermal imaging is used to capture the image of temperature distribution through PV panel. While ensuring the electrical output of the PV panel, current-voltage (I-V) measurements of the PV panel, as well as power charging of from battery were recorded in each experiment. The performances of PV panel are experimented with compared with different cooling mode operations as shown in Table 1.

Table1. Variation modes operation for experimental testing.

\begin{tabular}{cl}
\hline Modes & \multicolumn{1}{c}{ Operation } \\
\hline M1 & Reference (No cooling) \\
M2 & Forced convection with one unit of DC fan \\
M3 & Forced convection with two units of DC fan \\
M4 & Forced convection with three units of DC fan \\
M5 & Forced convection with four units of DC fan \\
\hline
\end{tabular}

\section{RESULTS AND DISCUSSION}

Different modes operation of cooling mechanism was carried out to evaluate the influence of number DC fan as cooling mechanism for PV panel used. The detail analysis of the electrical and thermal aspects of PV panel has been conducted hence the necessary number of DC fan required for one unit PV panel can be determined.

\subsection{Thermal Performance Characteristic}

As the main purpose to provide a reliable cooling system, determination of the temperature distribution of the PV panel is a crucial factor. Figure 4 describes the performance of ambient temperature and the average PV panel temperature of the backside PV panel for different mode operation. A PV system normally designed according to the average surrounding temperature at site location, which is primarily a product of the ambient temperature. The average ambient temperature through the experimental day is 36.50 ${ }^{\circ} \mathrm{C}$ while the maximum value reach at $39.21^{\circ} \mathrm{C}$.Generally, the PV panel temperature will be higher than ambient temperature.

As can be seen in this figure, PV panels without a cooling system are exploring experienced in high level of operating temperature. The maximum PV panel temperature found about $59.88{ }^{\circ} \mathrm{C}$ at $39.21{ }^{\circ} \mathrm{C}$ of ambient temperature for PV panel with no cooling attached. The high operating temperature normally produced during high-intensity solar radiation. When the energy of the incident radiation is higher than the band gap energy of semiconductor, a portion of photon energy will transform into heat rather than electrical 
energy. Thus, the production of heat energy will lead into increments of PV panel temperature. But when attaching the cooling system, at same condition, the PV panel temperature can be reduced to $53.64{ }^{\circ} \mathrm{C}$ with one unit DC fan act as cooling mechanism. Cooling mechanisms observed to have greatly influenced on temperature reduction through PV panels. The overall results implied the operating temperature obviously dropped with the increasing number of DC fan. As it can be seen, by using four units of DC fan as a cooling device, the average PV panel temperature most significantly reduced compared to other mode operations. By using four units of DC fans, the average PV panel temperature reduced about $22.22 \%$ respectively. The PV panel temperature observed to be nearly the value of the ambient temperature of the day. Apart, the distribution backside temperature for PV panel with attached two and three units of DC fan looks not too much different to the four unit DC fans. The different between these three modes operation only about 2-3\% of distribution temperature.

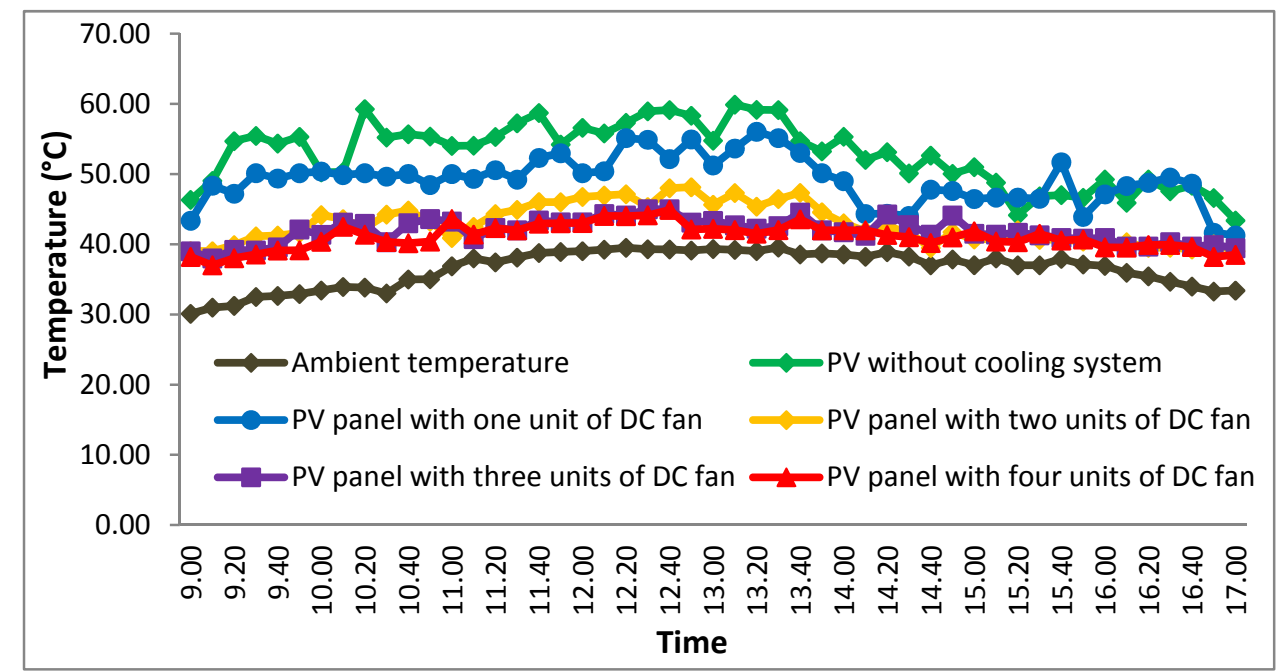

Figure 4. Comparative performance of PV panel temperature for five modes operation with ambient temperature

Solar systems are outdoor electrical installations exposed to variation temperature, stresses of wind, rain, melt, and UV radiation in weathering. To ensure reliable operation during the full lifetime cycle of a PV panel, thermal imaging camera can play an important role. All thermal images captured during the highest intensity of solar radiation. Figure 5 observed the temperature variation over the surface of the solar panel. Thermography technique utilizes the cooler spots of the system by looking at the blue colored areas of the system as compared to the red zones. It clearly shows that large temperature differences along the panel surface were detected between the system with and without the cooling system. The result reported that measured temperature ranges distributed from $31.1^{\circ} \mathrm{C}$ to $54.01{ }^{\circ} \mathrm{C}$ respectively. Hottest portion found on PV panel without cooling mechanism with the maximum temperature at $54.01^{\circ} \mathrm{C}$ at ambient temperature of $39.21^{\circ} \mathrm{C}$. High temperature distributed caused by existing difference temperature among surrounding and PV panel temperature. The difference in temperature will lead into heat generated and increased the operating temperature of PV panel. But by attaching four units DC fan, it was warm to $39.86^{\circ} \mathrm{C}$. In addition, the average PV panel temperature by using M3 and M4 almost achieved the temperature distributed by using M5 operation. While, the average temperature of M2 operation observed in high condition with the range above $40{ }^{\circ} \mathrm{C}$. Based on the result produced, the increase number of DC fans decreases the PV panel temperature as the heat was removed from the PV panel. 


\begin{tabular}{|c|c|c|c|c|c|}
\hline \multirow{2}{*}{\multicolumn{6}{|c|}{$\begin{array}{r}\text { Mode } \\
\text { Thermography }\end{array}$}} \\
\hline & & & & & \\
\hline Min temperature $\left({ }^{\circ} \mathrm{C}\right)$ & 40.49 & 36.89 & 32.67 & 31.67 & 31.10 \\
\hline Max temperature $\left({ }^{\circ} \mathrm{C}\right)$ & 54.01 & 49.89 & 41.31 & 40.06 & 39.86 \\
\hline Avg temperature $\left({ }^{\circ} \mathrm{C}\right)$ & 51.31 & 46.50 & 37.22 & 36.61 & 35.28 \\
\hline
\end{tabular}

Figure 5. Temperature distribution through the front surface PV panels for different mode operation

\subsection{Electrical Performance Analysis}

Different modes of cooling operation and without cooling (reference) were carried out to evaluate the impact of a number of fans in improved the performance of PV panel. The I-V characteristic of the PV panel in the experiment was measured in order to calculate the generated power output produced. Figure 6 shows the current output produced by each PV panel through the experiment. The current output for each mode operation observed started to be increased value from 11.00 a.m. to 2.00 p.m., which is at peak solar radiation and high ambient temperature. With the existing of cooling mechanism, the current output obtained slightly increased with the decreasing PV panel temperature. The current output of a PV panel cooled by DC fan is higher than that generated by no cooling attached. Such as an example, the highest current observed to be produced by using M5 mode operation by $4.97 \mathrm{~A}$ at $1.40 \mathrm{p} . \mathrm{m}$. during the highest ambient temperature. While, in the same condition, only 3.49 A have been produced when no cooling mode was attached. An increment in the current with a reduction in temperature is due to a marginal increase in the photo-generation rate, which in turn is due to a reduction in band gap energy [10].

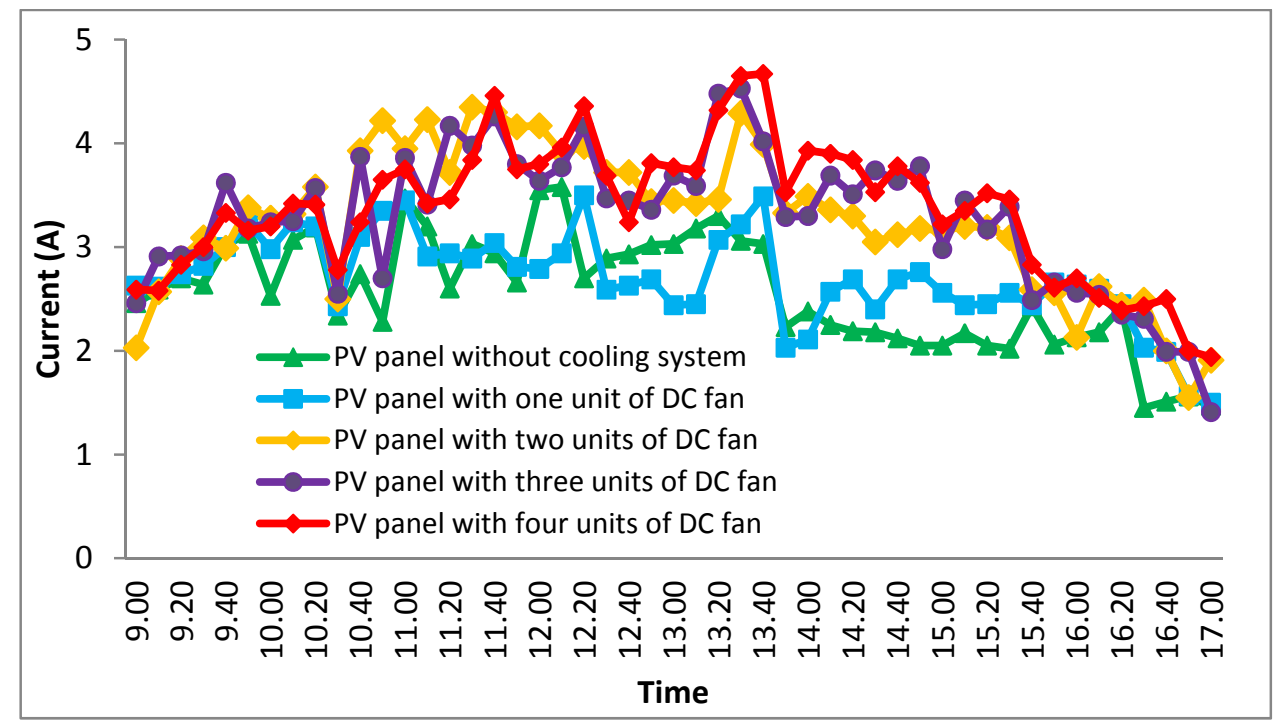

Figure 6. Current output of PV panel versus time operation for each mode operation

The effect on the different number of DC fans on voltage output of the PV panels compared with no cooling attached was illustrated as in Figure 7. As can be seen in this figure, the increment of the number DC 
fan will increase the voltage output of the PV panel. The main focused analysis is when the PV panel experienced in high ambient temperature, which is from 11.00 a.m. to 2.00 p.m. With almost in range above $15 \mathrm{~V}$, the increasing number of DC fan observed to give a great impact on voltage performance. Instead, at same condition, PV panel without cooling mechanism experienced in low voltage at high level of solar radiation. The lower voltage found in the highest ambient temperature which at mode operation with no cooling mechanism attached with $13.55 \mathrm{~V}$ of voltage output. As can be observed, the voltage output from M1 operation maintained with a low value at a high ambient temperature. Rising withthe temperature increase the dark current resulted decreasing in the band gap of the semiconductor, has a remarkable effect on voltage [11]. However, with existing cooling mechanism, the voltage output has improved their performance output at the same condition. With applying cooling mechanism, about 3.7\% increasing in voltage output can be produced. The percentage increments observed can be improved by increasing the number of DC fan to 2, 3 and 4 units respectively. About $14.5 \%$ of percentage increments in voltage output can be observed by attaching four units, DC fan at the backside PV panel. Thus, the development of cooling mechanism has a great impact in temperature reduction at the hot climatic weather.

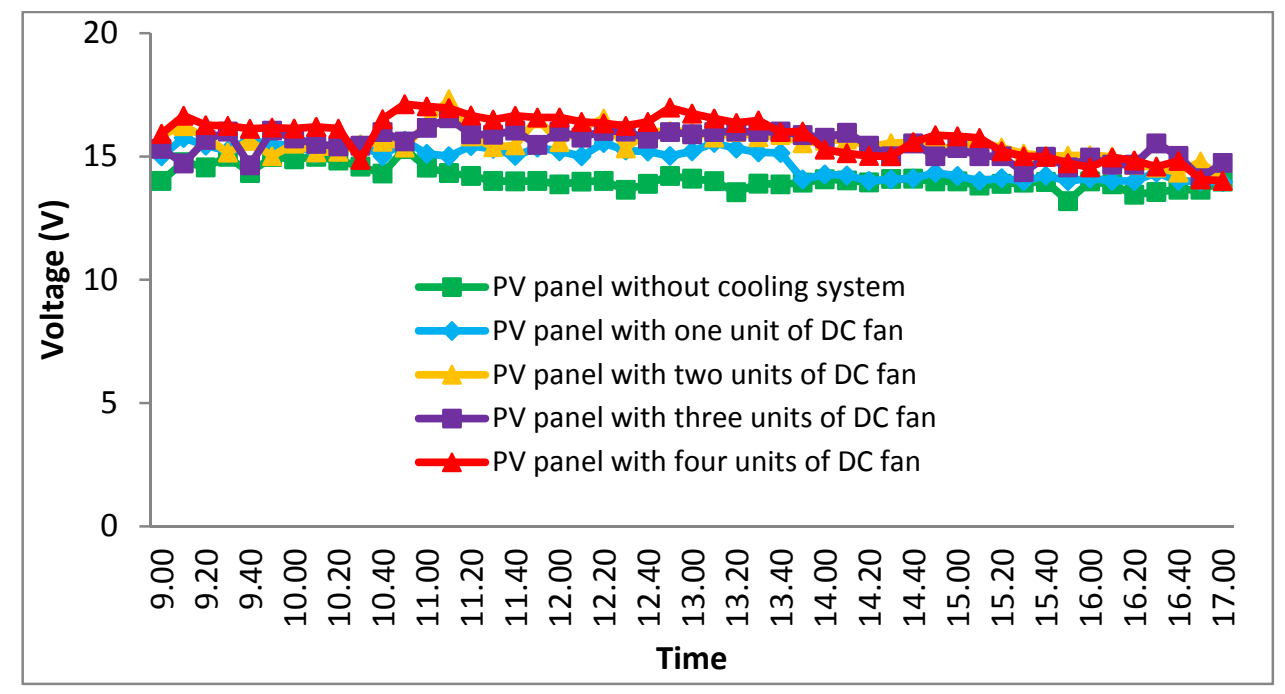

Figure 7. Voltage output of PV panel versus time operation for each mode operation

Figure 8 describes the overall total of power output generated by each mode operation. As shown in this figure, by increasing the number of DC fan, a remarkable increase in power output was found. Without applying cooling mechanism to the PV panel, only $42.53 \mathrm{~W}$ of power output can be produced at a higher ambient temperature. Lower in power output generated due to increase in operating temperature PV panels when more heat energy is produced rather than electrical energy. Instead, at same condition, it should be noticed that the power output is increased about $12.93 \%$ by introducing one unit DC fan for cooling PV panel. The figure has also revealed, without cooling mechanism attached to PV panel, the power output in a worst condition as PV operating temperature resulted in high condition. By further increasing the DC fan from 2 to 3 and 4, the power output increased to $67.70 \mathrm{~W}, 72.43 \mathrm{~W}$, and $76.54 \mathrm{~W}$ respectively. This corresponds to $37.17 \%, 41.28 \%$ and $44.34 \%$ increase power output of a PV panel. 


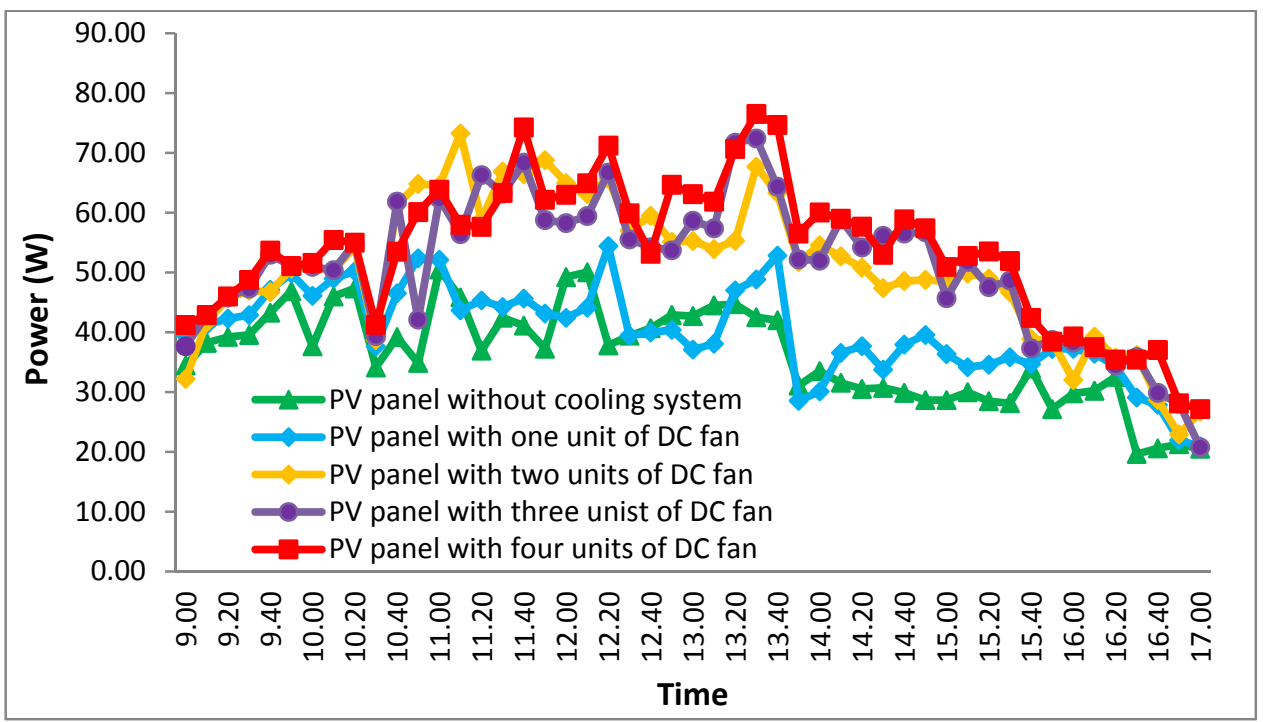

Figure 8. Power output of PV panel versus time operation for each mode operation

As expected, there is a clear trend of increasing in the power output of the PV panels by increasing the number of fans. This has happenedsince the PV transformation of solar energy to electricity increases on account of PV operating temperature decreases. Increasing the DC fan number improved the effect of heat transfer area of PV panel with more air circulation produced. However, the increase in the number of fans leads to more electrical power consumed, and more capital investment required. Thus, it is concluded that an increasing number of fans are not always leading to increasing total power output generated.

There have the number of fans required as cooling mechanism for PV panel to achieve maximum power output. The quantity of DC fan for a unit PV panel depends mainly on the total amount of heat needed to be removed. Besides, the size of PV panels and atmospheric factors of site location becomes the important factors in determining the necessary number of DC fan as cooling mechanism. By referring the thermal and electrical result, the necessary number of DC fans for the type PV panel used is two units respectively since there are not too much differed in output performance between three and four units DC fans. Furthermore, the installation cost of cooling mechanism for PV panel can be reduced with minimized the number of DC fan. Thus, the effective and economical PV system can develop with the existing cooling mechanism.

\section{CONCLUSION}

As conclude, this paper explored the impact of cooling mechanism for the overall performance of PV panel. In general, the increasing in operating temperature of PV panel caused by heat energy generated through PV panel. The increasing in temperature will lead to the decrement power output of the PV panels. Therefore, the cooling mechanism has been installed at the PV panel in order to solve this existing problem. By referring from the result produced, the PV panel without cooling mechanism experiences in high operating temperature. However, the existing cooling mechanism will reduce the PV panel temperature then increased its power output. The increasing number of DC fans leads to the decrease more PV panel temperature. Unfortunately, increasing in a number of DC fans will consume more energy from a PV panel. There is the optimum number of DC fan required for PV panel used. The selection of the number DC fan mainly depends on the several factors such as atmospheric condition, speed and airflow DC fan used and size of the PV panel. Furthermore, the existing cooling mechanism identified to be the energy-saving system with the PIC18F4550 micro controller acts as controller operation of the selection DC fan. It is because the electrical energy used from PV panel can be minimized with only operated during hot climate weather. Thus, the DC fan will not operate for 24 hours per day.

\section{ACKNOWLEDGEMENTS}

The authors thank the Centre of Excellence for Renewable Energy (CERE) in Kangar, Perlis for providing all data used in this study. 


\section{REFERENCES}

[1] M. Tripathy, P.K. Sadhu. Building Integrated Photovoltaic is a Cost Effective and Environmental Friendly Solution.TELKOMNIKA Indonesian Journal of Electrical Engineering. 2015; 14 (1): 49-54.

[2] F. Dincer , M.E. Meral. Critical factors that affecting efficiency of solar cells.Smart Grid and Renewable Energy. 2010; 1 (1):47-50.

[3] Hossein Shahinzadeh, Mohammad Moien Najaf Abadi, Mohammad Hajahmadi, Ali Paknejad. Design and Economic Study for Use the Photovoltaic Systems for Electricity Supply in Isfahan Museum Park. International Journal of Power Electronics and Drive System (IJPEDS). 2013; 3 (1): 83-94.

[4] H.G. Teo, P.S. Lee, M.N.A. Hawlader. An active cooling system for photovoltaic modules. Applied Energy. 2012; 90 (1): 309-315

[5] Z. Farhana, Y.M. Irwan, R.M.N. Azimmi, A.R.N. Razliana, N.Gomesh. Experimental investigation of photovoltaic modules cooling system.IEEE Symposium on Computers \& Informatics; 2012.

[6] O. Zogou, H. Stapountzis. Experimental validation of an improved concept of building integrated photovoltaic panels. Renewable Energy. 2011; 36 (12): 3488-3498.

[7] Y.M. Irwan, W.Z. Leow, M. Irwanto, Fareq. M, A.R. Amelia, N. Gomesh, I. Safwati. Analysis Air Cooling Mechanism for Photovoltaic Panel by Solar Simulator. International Journal of Electrical and Computer Engineering (IJECE). 2015; 5 (4): 636-643.

[8] S.K. Natarajan, T.K. Mallick, M. Katz, S. Weingaertner. Numerical investigations of solar cell temperature for photovoltaic concentrator system with and without passive cooling arrangements. International Journal of Thermal Sciences. 2011; 50 (12): 2514-2521.

[9] M.Z. Hussin, A.M. Omar, Z. Md Zain, S. Shaari, H. Zainuddin. Design Impact of 6.08 kWp GridConnectedPhotovoltaic System at Malaysia GreenTechnology Corporation. International Journal of Electrical and Electronic Systems Research. 2012; 5.

[10] A. Sahay, V.K.Sethi, A.C. Tiwari. Fabrication scheme, Instrumentation scheme and Testing of Ground Coupled Central Panel Cooling System (GC-CPCS). International Journal of Current Engineering and Technology. 2014; 4 (2): 631-638

[11] P.K. Dash, N.C. Gupta. Effect of Temperature on Power Output from Different Commercially available Photovoltaic Modules. International Journal of Engineering Research and Applications. 2015; 5 (1): 148-15. 